seemed very depressed, complained of pain in the abdomen, especially in the epigastrium, and was suffering from jaundice. She had a mitral systolic murmur, and the heart-sounds were feeble. Her liver was enlarged and tender, and her tongue furred. She gave me the following history. For some years she had been subject to epileptic fits, and on Wednesday, Nov. 4th, had had eleven distinct fits. Since then she had been getting worse, but did not send for advice sooner, as she haó suffered from similar attacks previously. (Nothing was said regarding her having taken poison, and after her death I found that she had never suffered from jaundice.) I diagnosed jaundice, due probably to gall-stones or to an irritant taken as food. Hot fomentations were ordered to be applied to the abdomen, milk diet to be taken, and podophyllin and taraxacum, with dilute nitro-hydrochloric acid, given. She died on the following day, having lived four days and a half from the date of taking the poison.

No post.mortem examination being ordered by the coroner, I received permission to make a partial one. The body was well developed. On opening the abdomen there was a distinct garlic-like odour. The hearb was fatty, and cavities empty. Posterior surfaces of lungs oedematous, and petechiæ scattered over these surfaces. The stomach was filled with a dark-brownish fluid having the smell of lucifer matches. The mucous membrane of the cardiac end was of normal appearance, but that of the pyloric end was deeply injected, and of a deep crimson colour. The transition in colour between the two halves of the stomach was sudden. No ulceration present; no peritonitis. Intestines empty and normal in appearance, except at the upper end of the duodenum. The liver was enlarged, fatty, and very friable. Uterus fatty, and membrane similar in colour to that of the pyloric end of the stomach. The bladder contained urine. The kidneys were slightly fatty.

The above is another instance of the ease with which one can obtain the most dangerous poisons for the purpose of taking away life, and though the deceased was in a state of semi-intoxication when she purchased the poison, she had no difficulty in obtaining it.

Stamford-hill, $\mathbf{N}$.

\section{CHROMIC ACID IN THE TREATMENT OF CYSTS.}

By W. R. H. Stewart, F.R.C.S. Edir. \&c.

WITHIN the last few months I have treated with chromic acid three cases of ranula and seven of cystic goitre with such satisfactory results that $I$ venture to make them known.

The three cases of ranula occurred in two males and one female: the former had received previous treatment without any benefit; the latter had not sought advice before. All three had large cysts, and the mode of treatment followed was the same in each. A portion of the cyst was cut away, and the contents washed out. A saturated solution of chromic acid was then freely applied with a chromic acid carrier to several points of the cyst wall. At the end of the week, the cavity having much diminished, the acid was again applied, and in from a fortnight to three weeks the wound had healed and all signs of the tumour had disappeared. There were no bad symptoms.

The seven cases of cystic goitre were in females. The tumours were tapped in the usual manner and the contents washed out. After all hæmorrhage had ceased, the saturated chromic acid solution was applied with a carrier through the cannula to the walls of the cyst, in the same manner as with the ranulas. Six of the seven cases healed rapidly after from two to three applications, but the seventh and second of the series resisted for a long time all attempts, and it was not until three months had passed and some half.a.dozen applications had been made that the tumour disappeared. But neither in this nor in any of the other cases was there a bad symptom, and I attribute the length of time the last-mentioned case took to heal to the fact that there was a considerable amount of bæmorrhagic oozing, which to a certain extent neutralised the action of the acid. It is therefore advisable to see that hæmorrhage is, as much as possible, arrested before applying the acid.
I cannot too strongly recommend this mode of treat. ment (first suggested by Dr. Woakes in THE LANCET about two years ago), and though the evidence I have been able to offer is not very great-ten cases in all, - still the per. sistent favourable results obtained are, I think, strongly in favour of a good trial being given to it, not only in the same class of cases as those I have quoted, but in every case of cyst that it is unadvisable or impossible to remove. In cystic goitres it seems entirely to do away with the most dangerous part of the ordinary treatment-viz, the con. version of the cyst into a large abscess.

Devonshire-street, W.

\section{MATERNAL IMPRESSIONS.}

By Archibald Mackay, M.D.

I HAVE read with much interest the remarks on Dr. Lee's cases of maternal impressions in THE LANCKT of the $21 \mathrm{st}$ ult. As I have met in my practice with several cases in which marks on the child have been ascribed by the mother to fright or other causes experienced during pregnancy, the following notes may be of interest.

The first case which came under my observation was that of a young girl with an oblong patch of soft dark hair on the left cheek, extending from the ear downwards to the neck. The mother stated that while pregnant she was working in the field at haymaking, when her husband threw a young hare, which he had found in the hay, at her, striking her on the cheek and neck in the exact place where the patch of hair was found on the child at birth. The colour and character of the hair on the patch closely resembled the fur of a very young hare.

The second case was that of a lady who, on entering ber kitchen when pregnant, found the servant with a paraffin lamp on fire. She happened to place her hand on the back of her neck at the moment, and turned away immediately lest the shock might induce a niscarriage. The child (a male) was born at full time, and when examined had a rea' discolouration of the skin on the back of the neck, extending upwards towards the occiput, in pointed tips, not unlike a flame in shape and appearance.

The third case was also a male child. The mother, immediately after the child was dressed, inquired if he had any marks. I asked her to tell me what kind of mark she expected, and where I was to look for it. She replied, "Lools. on the top of the head for a mouse mark." When the head was examined, a brown oval patch was found on the spot indicated. The mother in this care did not see the child, and the mark was not observed until she had made inquiry about it. It seems that when pregnant, on opening a press. a mouse jumped out at her feet, causing a sudden shock, and she involuntarily placed her hand on the top of her head in the exact spot where the patch was found on the child.

The fourth case, a male child, when born had a raised. bluish mark on the mucous membrane of the lower lip. The mother said she could only account for it by ber having great sympathy with a friend who was in bad health at the time she was pregnant, and who had a venous nævas on the lower lip in the same place as on the child's lip.

The fifth case was that of a female child with a circular pinkish mark on the left arm above the elbow. The mother ascribed the cause to ungratified desire. When walking past a gentleman's grounds she saw a flowering rhododendron which she stood to admire, and happened to catch her left arm above tbe elbow with the right hand, being about. five months pregnant at the time, and to this cause she attri. buted the mark on the child.

In these cases the first three were attributed to sudden fright, the part touched at the moment the shock was received being the part affected in the child, the fourth to sympathy, and the fifth to a wish ungratified. The exact period of gestation at which the impressions were received I have not been able to find out, but, as far as could be ascerbained, it was between the fourth and sixth month. The mothers in all these cases. were strong and healthy, and the infants well developed and born at full time.

Port Appin, N.B. 